\title{
Proteomic Analysis Provides Insights into Arabidopsis thaliana Response Under Narrow-Wavelength LED of $595 \mathrm{~nm}$ light
}

\author{
Nafiseh Yavari*, Mark G. Lefsrud \\ Department of Bioresource Engineering, McGill University, Sainte-Anne-de-Bellevue, QC, Canada
}

\begin{abstract}
A growing body of evidence has highlighted that a wide range of plant processes including growth, photosynthesis, and stress response are regulated by $595 \mathrm{~nm}$ light. However, the molecular mechanisms underlying $595 \mathrm{~nm}$-induced signals are not known. The aim of this work was to study the comparative proteomic changes in leaves of Arabidopsis thaliana Col-0 plants treated with narrow-wavelength $595 \mathrm{~nm}$ light or fluorescent light for 5 days. Harvested plant samples were analyzed using inline RP-SCX-RP liquid chromatography coupled with LTQ mass spectrometer, resulting in the identification of 1538 proteins. Linear regression modeling of proteins' relative abundance revealed a total of 23 differentially abundant proteins (DAPs). Functional analysis of these DAPs demonstrated the role of several biological mechanisms in A. thaliana's response to $595 \mathrm{~nm}$ light including stress response and metabolic processes. A network analysis of these DAPs revealed the importance of energy and redox regulation mechanisms. Further analyses determined potentially important roles for proteins associated with glycolysis, ATP synthase complex, cell wall modification, and thylakoid membrane that may modulate the plant's adaptive response to $595 \mathrm{~nm}$ light. A significant enrichment of DAPs for PSII tolerance capacity, as well as associated $\mathrm{Ca}^{+}$and ROS signaling pathways were also identified. Collectively, this study provides an important insight into potential molecular pathways that sustain a plant's response to $595 \mathrm{~nm}$ light.
\end{abstract}

Keywords: Adaptation; Arabidopsis thaliana; Light Wavelength; Protein Network; Quantitative Proteomic; Stress Response; Tolerance Response; Mass Spectrometry; Liquid Chromatography; Light Emitting Diode LED

\section{INTRODUCTION}

The spectral quality of the radiation, adopted by plant production systems, efficiently drives plant growth and development [1]. It is therefore possible to influence plant adaptation and tolerance by controlling light-signal mechanisms to significantly improve agricultural production [2]. For example, a five-fold increase in annual greenhouse cucumber productivity from 50 to $250 \mathrm{~kg} /$ $\mathrm{m}^{2}$ was reported by controlling the spectral light climate. With the increasing effects of climate change and a rapidly increasing world population, controlled environment agriculture is a promising solution to these global challenges [3]. Understanding the mechanisms that underlie plant spectral light responses and tolerance is hence paramount to improve plant agriculture productivity and global food security. Within the photosynthetically active radiation (PAR) light spectrum $(400-700 \mathrm{~nm})$, plant photoreceptors perceive the major wavelengths corresponding to blue $(400-500 \mathrm{~nm})$ and red $(600-700 \mathrm{~nm})$ regions, and less within the green $(500-600 \mathrm{~nm}$ ) [4]. While only $10-50 \%$ of these regions are reflected by plant chloroplasts [5], there is a misconception that plants do not make use of the wavelengths regions $(500-600 \mathrm{~nm})$ [6].Within this region, there is a narrow wavelength with a peak at $595 \mathrm{~nm}$ that a growing body of evidence has highlighted for its physiological impact on plants growth and photosynthesis $[7,8]$. For example, reported consequences of $595 \mathrm{~nm}$ include reduction in growth, chlorophyll content, photochemical quenching and quantum efficiency of PSII photochemistry. This wavelength is weakly absorbed by photosynthetic pigments [5], and $595 \mathrm{~nm}$ wavelength is arguably a less efficient light energy source for driving photosynthesis [9-12]. Congruently, under $595 \mathrm{~nm}$, the activity of Rubisco decreases which may be due to a reduction in photosynthesis. Plant illumination with $595 \mathrm{~nm}$ results in elongation and less leaf area. Furthermore, a decrease in $\mathrm{CO}_{2}$ fixation and net photosynthesis, leading to reduced growth and yield has been reported [11,12]. However, McCree showed that 595 nm light exhibits some of the highest photosynthetic activity of any of the other wavelengths of light tested [13]. Additionally, $595 \mathrm{~nm}$ light plays a highly regulatory role in abundance and activity of key proteins that mediate stress tolerance in plant [14]. For instance, $595 \mathrm{~nm}$ light induces the abundance/activity of antioxidant

Correspondence to: Nafiseh Yavari, Department of Bioresource Engineering, McGill University, Sainte-Anne-de-Bellevue, QC, Canada, Tel: +(514)3987773; E-mail: Nafiseh.yavari@mail.mcgill.ca

Received: November 25, 2019, Accepted: December 23, 2019, Published: December 30, 2019

Citation: Yavari N, Lefsrud MG (2019) Proteomic Analysis Provides Insight into Arabidopsis thaliana's Response to Narrow-Wavelength 595 nm Light. J Proteomics Bioinform 12:507 doi: 10.35248/0974-276X.19.12.507

Copyright: $\odot 2019$ Yavari N, et al. This is an open-access article distributed under the terms of the Creative Commons Attribution License, which permits unrestricted use, distribution, and reproduction in any medium, provided the original author and source are credited. 
enzymes such as superoxide-dismutase (SOD), catalase (CAT), and peroxidase (POD), ultimately reducing the accumulation of free radicals. Thus, $595 \mathrm{~nm}$ light regulates an integrated molecular network at multiple levels to bring about tolerance responses. Despite being a probable light source for understanding regulatory signals in plant growth and development related to stress and tolerance responses, the molecular mechanisms and impact on plant growth underlying the effect of $595 \mathrm{~nm}$ light remain unclear. Plants have developed a sophisticated sensory system to optimally grow and regulate numerous developmental processes under ambient light quality conditions [15,16]. A variety of receptor molecules, often proteins, are involved in monitoring radiation, and consequently transduce signals to trigger a response [17]. The signal-response network often involves complex interactions between signal transduction and many different processes to regulate translational responses and protein expression throughout the whole plant [18]. Proteomic techniques are a powerful means of detecting quantitative variations in relative protein abundance and fundamental cellular biological processes in response to a defined set of environmental conditions [19]. To investigate the molecular mechanism underlying plant responses to $595 \mathrm{~nm}$ light, a RP-SCXRP liquid chromatography coupled with LTQ mass spectrometer was applied. As studies have demonstrated that plant growth, photosynthesis and developmental responses to $595 \mathrm{~nm}$ light are directly opposed to the normal progression of light-mediated processes, we compared the changes in proteins abundance of the model plant Arabidopsis thaliana treated under $595 \mathrm{~nm}$ light and fluorescent light (FL), as the control. The obtained data indicate that many proteins are differentially expressed (activated or repressed) in plants grown under $595 \mathrm{~nm}$ light. Enriched proteins were involved in photosynthesis, metabolic processes, stress response, and ROS signaling. This study highlights light wavelength-regulated molecular networks and potential pathway crosstalk in plants tolerance response under $595 \mathrm{~nm}$ light.

\section{MATERIALS AND METHODS}

\section{Plant material and growth conditions}

Seeds of the Arabidopsis thaliana accession Col-0 were obtained from the Arabidopsis Biological Resource Center (ABRC; https:// www.arabidopsis.org). Seeds were dark-incubated at $4^{\circ} \mathrm{C}$. After 2 days, germinated seeds were placed in rockwool cubes (Grodan A/S, DK-2640, Hedehusene, Denmark) and grown hydroponically for 21 days at a photosynthetic photon flux density (PPFD) of $70 \mu \mathrm{mol} \cdot \mathrm{m}^{-2} \cdot \mathrm{sec}^{-1}$ of fluorescent lamps (FL; $4200 \mathrm{~K}, \mathrm{~F} 72 \mathrm{~T} 8 \mathrm{CW}$, Osram Sylvania, MA, US) (Figure 1A) under a $16 \mathrm{~h}$ photoperiod in a growth chamber (TC30, Conviron, Winnipeg, Canada). The low light PPFD $\left(70 \mu \mathrm{mol} \cdot \mathrm{m}^{-2} \cdot \mathrm{sec}^{-1}\right)$ was used to limit light-induced stress responses [20]. Seeds density was adjusted to prevent 21-day old plant leaves from shadowing each other. PPFD was measured over the growing area $(49 \mathrm{~cm} \times 95 \mathrm{~cm})$ using a grid size of $3 \mathrm{~cm}^{2}$ for each reading to provide uniform distribution of light over the growing surface. Fresh half-strength Hoagland nutrient solution [21] was provided every other day.

\section{Light treatments}

A customized light emitting diode (LED) array with a precisely measured single-emission narrow peak of $595 \mathrm{~nm}$ (VanqLED, Shenzhen, China) was used for light treatments (Figure 1A). After 21-day growth under FL, 80 plants were randomly divided into two groups and treated for 5 days under $595 \mathrm{~nm} \mathrm{LED} \mathrm{or} \mathrm{FL}$ light of a wide spectral emission range $(400-700 \mathrm{~nm})$ with the following environmental conditions: $16 \mathrm{~h}$ photoperiod, $23 / 21^{\circ} \mathrm{C}$ (day/night), 50\% relative humidity, and ambient $\mathrm{CO}_{2}$ levels. Wavelength spectra of the LED and FL lights were measured using a PS-300 spectroradiometer (Apogee, Logan, UT, US). After 5 days of treatment, 30 plants were randomly harvested as a single sample, immediately frozen in liquid nitrogen, and stored at $-80^{\circ} \mathrm{C}$ for protein extraction. The above-mentioned experiments were repeated three times to provide three biological replicates.
A)

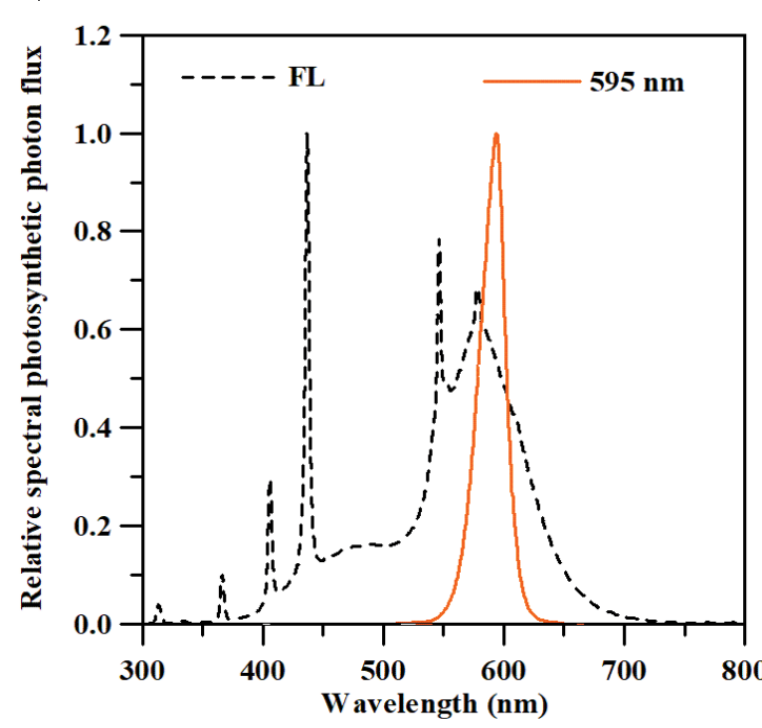

B)

FL

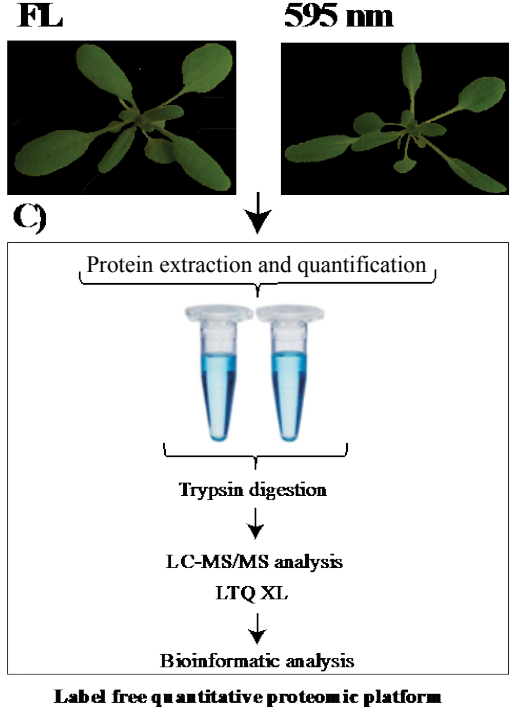

Figure 1: Growth response and comparative proteomic analysis of A. thaliana to narrow-wavelength $595 \mathrm{~nm}$ and FL. A) Represents the emission spectra of light sources: $595 \mathrm{~nm}$ and FL. B) Represents the morphology of 26-day-old plants of A. thaliana Col-0 treated for 5 days with $595 \mathrm{~nm}$ and FL. C) Represents the proteomic workflow; in-solution digested proteins were identified by in-line LCLTQ. (Three biological replicates were analyzed) . 


\section{Protein extraction and digestion}

Frozen samples were ground in liquid nitrogen using a mortar and pestle, prior to protein extraction and digestion [22], adapted here for A. thaliana. Briefly, $100 \mathrm{mg}$ of ground plant tissue was homogenized on ice in $100 \mu \mathrm{L}$ lysis buffer (Tris/10 $\mathrm{mM} \mathrm{CaCl}_{2}$ at pH 7.6 and 6 M guanidine/10 mM DTT) (Sigma-Aldrich Canada, Oakville, ON). The solution was boiled for $5 \mathrm{~min}$ and vortexed every $2 \mathrm{~min}$ for the first hour before being incubation at $37^{\circ} \mathrm{C}$ for $12 \mathrm{~h}$. Solubilized mixtures were sonicated in an ice bath with $40 \%$ amplitude for two cycles of $60 \mathrm{~s}$ each, with a $30 \mathrm{~s}$ cool-down period between cycles (Crystal Electronics, Stamina-XP Ultrasonicator, Newmarket, ON, Canada). The protein extract was boiled for $5 \mathrm{~min}$ prior to centrifugation $\left(3000 \mathrm{~g}\right.$ ) at $25^{\circ} \mathrm{C}$ for $15 \mathrm{~min}$ (Beckman Avanti J25-I, Brea, CA). Finally, the protein concentrations in the lysates were quantified using a BCA Protein Assay Kit (ThermoFisher Scientific, Waltham, MA, US). Aliquots containing $200 \mu$ g protein were reduced with $25 \mathrm{mM}$ DTT, followed by protein precipitation with trichloroacetic acid. Samples were centrifuged at $4500 \mathrm{~g}$ for $10 \mathrm{~min}$ before washing with ice-cold acetone to remove lipids and excess SDS. Pellets were re-suspended in 250 ul of $8 \mathrm{M}$ urea, 100 $\mathrm{mM}$ Tris- $\mathrm{HCl}, \mathrm{pH} 8.0$ using sonic disruption and incubated for 30 min at room temperature. Denatured proteins were reduced with $5 \mathrm{mM}$ DTT. To prevent reformation of disulfide linkages, cysteines were blocked with $20 \mathrm{mM}$ iodoacetamide.

Sequencing-grade trypsin (Promega, Madison, WI, US) was diluted with $50 \mathrm{mM}$ Tris/10 $\mathrm{mM} \mathrm{CaCl}_{2}$. Cysteine-blocked protein pellets were suspended in two aliquots of sequencing-grade trypsin (1:50 $\mathrm{w} / \mathrm{w}$ ), then incubated overnight at $37^{\circ} \mathrm{C}$, followed by the addition of a second aliquot of trypsin and incubation for $4 \mathrm{~h}$, followed by the addition of $1 \mathrm{M}$ DTT to a final concentration of $20 \mathrm{mM}$. Following digestion, peptide samples were centrifuged for $10 \mathrm{~min}$ at $4500 \mathrm{~g}$ (VWR Costar model V, Radnor, PA) and pellets were discarded. The supernatant was adjusted to $200 \mathrm{mM} \mathrm{NaCl}, 0.1 \%$ formic acid and filtered through an Ultrafree- MC $45 \mu \mathrm{m}$ spin filter (Ultrafree-MC UFC30HV00, pore size $0.45 \mu \mathrm{m}$, EMD Millipore, Billerica, MA). The peptide concentration was quantified using a BCA Protein Assay Kit before being stored at $-80^{\circ} \mathrm{C}$ until mass spectroscopy (MS) analysis.

\section{LC-MS/MS}

Peptide analysis was conducted using inline three phasic (RP-SCXRP) HPLC coupled to a linear ion trap mass spectrometer (LTQ, Thermo Fisher Scientific, San Jose, CA, USA) [23]. A total of 50 $\mu \mathrm{g}$ peptides were loaded onto an in-house, packed $75 \mu \mathrm{m}$ inner diameter biphasic back column containing $\sim 3-5 \mathrm{~cm}$ strong cation exchange resin for charge-based separation of peptides followed by $\sim 3-5 \mathrm{~cm} \mathrm{C}{ }_{18} \mathrm{RP}$ for online washing and removing residual urea

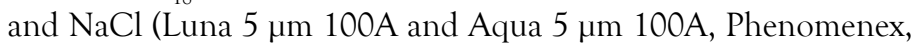
Torrance, CA) [24]. Each loaded column was first washed for 30 min off-line with LC-MS grade $\mathrm{H}_{2} \mathrm{O}(\mathrm{O} .1 \%$ F.A) to remove salts before being placed in-line with a front column including a nanospray emitter tip (150 $\mu \mathrm{m}$ with $15 \mu \mathrm{m}$ tip; New Objective, Woburn, MA). The front column was packed with $\sim 15-20 \mathrm{~cm}$ of $\mathrm{C}_{18}$ RP resin for hydrophobicity-based separation of peptides, adapted from previously described methods [24]. The analysis was conducted via LC-MS/MS in 12 steps of a $5-30 \%$ ACN gradient and $0.125 \%$ FA over $180 \mathrm{~min}$ at a flow rate of $400 \mathrm{nl} / \mathrm{min}$. Data were acquired in a positive mode by Data-Dependent Acquisition (DDA) operated by the software Xcalibur (v2.0.7) (Thermo Fisher Scientific, CA, USA). Survey scan was followed by the CID MS/ MS and high energy collision dissociation MS/MS of the 5 most intense ions in the LTQ for CID at 35 normalized collision energy, $3 \mathrm{~m} / \mathrm{z}$ isolation width, $10 \mathrm{~ms}$ activation time, and previously fragmented ions were dynamically excluded for $30 \mathrm{~s}$.

\section{Protein identification}

For each light condition, three biological replicates were tested. By injecting the same sample either one or two times as technical replicates; as a result, six and five samples were generated overall for the $595 \mathrm{~nm}$ light and FL control samples, respectively. The acquired LC-MS/MS spectra were extracted from Thermo RAW files that corresponded to each biological or technical replicate. Raw files were converted into MS2 files using RawXtract software, followed by conversion into mass lists using the Raw Extract 1_9_8 program [25]. The raw data files were processed and quantified using PatternLab for Proteomics software (v4.0.0.62) (available at: http://www.patternlabforproteomics.org/) [26]. Peptide sequence matching (PSM) was performed using the Comet algorithm [27] against the UniProt database (http://www.uniprot.org/) with A. thaliana protein entries downloaded August 2017, containing mitochondria, chloroplast proteins, and common contaminant proteins (i.e. bovine trypsin and human keratin). The search considered semi-tryptic peptide candidates. The oxidation of methionine was considered as a variable modification. The Comet search engine considered a precursor mass tolerance of $450 \mathrm{ppm}$. Because of the low resolution of LTQ-XL technology, we performed a second round of search to ensure the robustness of the result. To this aim, MS2 files were searched with ProLuCID search engine [28] against a sequence database used for PatternLab's Comet search engine. Parameters used for performing the searches were semi-tryptic hydrolysis allowing up to two missed cleavages, for both precursor tolerance and fragment tolerance of $500 \mathrm{ppm}$. The PSM provided by ProLuCID were subsequently filtered through the PatternLab's Search Engine Processor (SEPro) module [29]. The same conclusion was reached using these two search engines. The default on SEPro for both data was set on low resolution MS1 and experiment with more than 50k spectra. All identification results are reported with $<1 \%$ FDR at the peptide level based on the number of labeled decoys. Spectral counts were normalized using normalized spectral abundance factor (NSAF) approach that is widely used for the quantitative analysis of label free proteomics experiments [30]. Normalized spectral counts for each protein was next compared between the two light conditions using the T-Fold approach implemented in PatternLab software [31]. Proteins were deemed as differential abundant by setting two criteria: minimum fold change of 1.5, a Benjamini-Hochberg corrected p-value (FDR) of 0.05. To further confirm the significance of identified differentially abundant proteins, we compared their fold changes of the differentially abundant proteins under $595 \mathrm{~nm}$ in an independent dataset [32]. To assess the significance of the results, iterating 10000 times, we randomly permutated the fold change patterns in the independent dataset. Empirical p-value was next estimated by comparing the number of differentially abundant proteins that are consistently up or down regulated in both datasets with the distribution of what that is expected by chance. 


\section{Function annotation and classification of the DAPs}

Protein-protein interaction (PPI) networks were performed for all differentially abundant proteins using the Search Tool for the Retrieval of Interacting Genes/Proteins (STRING) database. The data setting for PPI construction was set as follows; organism: Arabidopsis thaliana, and minimum required interaction score: highest confidence (0.7). The hub node identification was conducted using Cytoscape 3.4.0 [33]. Enrichment analysis for biological process annotations were performed on DAPs using the BiNGO database databank available as a tool inside Cytoscape [33]. Enrichment analyses for metabolic pathway annotations were conducted on DAPs using the Kyoto Encyclopedia of Genes and Genomes (KEGG) database as a tool inside STRING.

\section{RESULTS}

\section{A. thaliana Col-0 growth response to narrow-wavelength $595 \mathrm{~nm}$ light}

Twenty-one-day-old A. thaliana Col-0 grown from seed under FL light were treated with $595 \mathrm{~nm}$ LED light or FL (Figure 1A) for 5 days. After treatments, plants treated with $595 \mathrm{~nm}$ LED light showed morphological changes indicative of weak light absorption, including smaller leaves with longer petioles, when compared with control plants treated with FL (Figure 1B).

\section{A. thaliana Col-0 proteomic response to narrow- wavelength $595 \mathrm{~nm}$ light}

To investigate proteomic changes in plants response associated with $595 \mathrm{~nm}$ light, LC-MS/MS analysis was performed on proteins extracted from leaves of A. thaliana Col-0 plants treated with 595 $\mathrm{nm}$ or FL light for 5 days (Figure 1C). LTQ certified the presence of 991 proteins, detected with at least two unique peptides across all samples. Of these identified proteins, a total of 334 proteins were detected three times through proteomic analysis of three independent biological replicates for each light condition. Proteins with significant abundance changes (fold change $\geq 1.5$ and FDR $\leq$ 0.05 ) in response to $595 \mathrm{~nm}$ versus FL are listed in Table 1. A total of 23 unique proteins met the criteria that indicated differentially abundant proteins (DAPs). Among these DAPs, expression of 14 proteins was up-up-regulated, while the expression of 9 other proteins was down-regulated, when treated with $595 \mathrm{~nm}$ light.

Functional annotation of differentially abundant proteins in A. thaliana Col-0 treated with narrow-wavelength 595 nm light

To identify mechanisms involved in the plant response to narrowwavelength $595 \mathrm{~nm}$ light, we annotated the DAPs via the GO function and KEGG pathway enrichment analysis using BiNGO and the STRING database, respectively. A total of $143 \mathrm{GO}$ terms and 10 KEGG terms were identified with Benjamini-Hochberg corrected false discovery rate (FDR) $<0.05$ (Figure 2; Table 2). The enriched GO terms were associated with various biological processes, including response to stimulus, response to stress, and small molecule metabolic processes. The overrepresented GO cellular component terms included chloroplast, membrane, and cytoplasm. The enriched GO molecular function categories were

Table 1: List of differentially abundant proteins in A. thaliana treated with narrow-wavelength $595 \mathrm{~nm}$.

\begin{tabular}{|c|c|c|c|c|c|c|}
\hline No. ${ }^{a}$ & Protein number ${ }^{b}$ & Protein name $e^{c}$ & Protein Description & Sub-localization $^{\mathrm{d}}$ & Fold change & p-value \\
\hline \multicolumn{7}{|l|}{$\mathrm{Up}^{\mathrm{e}}$} \\
\hline \multicolumn{7}{|c|}{ Photosynthesis $^{\mathrm{f}}$} \\
\hline 1 & P56778 & PSBC & PSII CP43 reaction center & $\mathrm{CY}$ & 1.81 & 0.041 \\
\hline 2 & Q01908 & ATPC1 & ATP synthase gamma chain 1 & $\mathrm{CL}$ & 1.57 & 0.029 \\
\hline \multicolumn{7}{|c|}{ Carbon and amino acid metabolism } \\
\hline 3 & Q42472 & GAD2 & Glutamate decarboxylase 2 & $\mathrm{CY}$ & 6.83 & 0.012 \\
\hline 4 & P10795 & RBCS-1A & $\begin{array}{l}\text { Ribulose bisphosphate carboxylase small chain } \\
1 \mathrm{~A}\end{array}$ & $\mathrm{CL}$ & 2.36 & 0.033 \\
\hline 5 & O50008 & MS1 & $\begin{array}{l}\text { 5-methyltetra-hydropteroyl triglutamate- } \\
\text { homocysteine methyltransferase } 1\end{array}$ & $\mathrm{CY}$ & 2.16 & 0.023 \\
\hline 6 & P48491 & TPI & Triosephosphate isomerase & $\mathrm{CY}$ & 1.93 & 0.031 \\
\hline 7 & Q9SRV5 & MS2 & $\begin{array}{l}\text { 5-methyltetra-hydropteroyl triglutamate- } \\
\text { homocysteine methyltransferase } 2\end{array}$ & $\mathrm{CY}$ & 1.8 & 0.01 \\
\hline 8 & P25696 & $\mathrm{ENO} 2$ & $\begin{array}{l}\text { Bifunctional enolase } 2 / \text { transcriptional } \\
\text { activator }\end{array}$ & $\mathrm{N}$ & 1.62 & 0.023 \\
\hline \multicolumn{7}{|c|}{ Cytoskeleton and cell wall } \\
\hline 9 & O49006 & PME3 & $\begin{array}{c}\text { Pectinesterase/ } \\
\text { pectinesterase inhibitor } 3\end{array}$ & CW & 2.48 & 0.008 \\
\hline \multicolumn{7}{|c|}{ Protein synthesis, folding and degradation } \\
\hline 10 & P22953 & HSC70-1 & $\begin{array}{c}\text { Probable mediator of RNA polymerase II } \\
\text { transcription subunit 37e }\end{array}$ & $\mathrm{N}$ & 5.61 & 0.034 \\
\hline 11 & Q94K05 & CCT8 & T-complex protein 1 subunit theta & CY & 3.63 & 0.043 \\
\hline \multicolumn{7}{|c|}{ Transportation } \\
\hline 12 & Q9SJT9 & AT2G21390 & Coatomer subunit alpha-2 & $\mathrm{CY}$ & 2.54 & 0.047 \\
\hline
\end{tabular}




\begin{tabular}{|c|c|c|c|c|c|c|}
\hline 13 & P31167 & $\mathrm{AAC} 1$ & ADP, ATP carrier protein 1 & M & 2.04 & 0.006 \\
\hline \multicolumn{7}{|c|}{ Signaling and defense } \\
\hline 14 & Q9SYT0 & ANN1 & Annexin D1 & PM & 2.98 & 0.03 \\
\hline \multicolumn{7}{|c|}{ Down } \\
\hline \multicolumn{7}{|c|}{ Photosynthesis } \\
\hline 15 & Q94BS2 & MET1 & Protein MET1 & $\mathrm{CL}$ & 0.39 & 0.036 \\
\hline 16 & Q9C9I7 & PSB33 & Rieske (2Fe-2S) domain-containing protein & $\mathrm{CL}$ & 0.32 & 0.033 \\
\hline \multicolumn{7}{|c|}{ Carbon and amino acid metabolism } \\
\hline 17 & Q39161 & NIR1 & Ferredoxin-nitrite reductase & $\mathrm{CL}$ & 0.5 & 0.038 \\
\hline 18 & Q9LF98 & FBA8 & Fructose-bisphosphate aldolase 8 & $\mathrm{CY}$ & 0.34 & $2 \mathrm{E}-04$ \\
\hline \multicolumn{7}{|c|}{ Protein synthesis, folding and degradation } \\
\hline 19 & Q9SZD6 & EF-Ts & Elongation factor $\mathrm{Ts}_{\mathrm{s}}$ & M & 0.46 & 0.014 \\
\hline \multicolumn{7}{|c|}{ Transportation } \\
\hline 20 & Q9FMF7 & DIT2-1 & Dicarboxylate transporter 2.1 & $\mathrm{CL}$ & 0.58 & 0.044 \\
\hline \multicolumn{7}{|c|}{ Signaling and defense } \\
\hline 21 & Q9ZUC1 & AOR & $\begin{array}{l}\text { Quinone oxidoreductase-like protein } \\
\text { At1g23740 }\end{array}$ & $\mathrm{CL}$ & 0.55 & 0.043 \\
\hline 22 & Q9C5R8 & AT5G06290 & 2-Cys peroxiredoxin BAS1-like & $\mathrm{CL}$ & 0.35 & 0.03 \\
\hline 23 & Q949U7 & PRXIIE & Peroxiredoxin-2E & $\mathrm{CL}$ & 0.28 & 0.043 \\
\hline
\end{tabular}

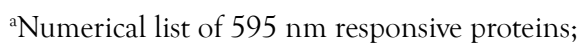

bProtein number and the abbreviation commonly used for the protein.

cProtein name given by Uniprot_Arabidopsis database.

dSubcellular localization of each protein given by the PPDB database.

eProtein expression pattern; upregulated and downregulated.

fFunctional group.

CL: Chloroplast; CW: Cell Wall; CY: Cytoplasm; N: Nucleus; PM: Plasma Membrane; PSII: Photosystem II.
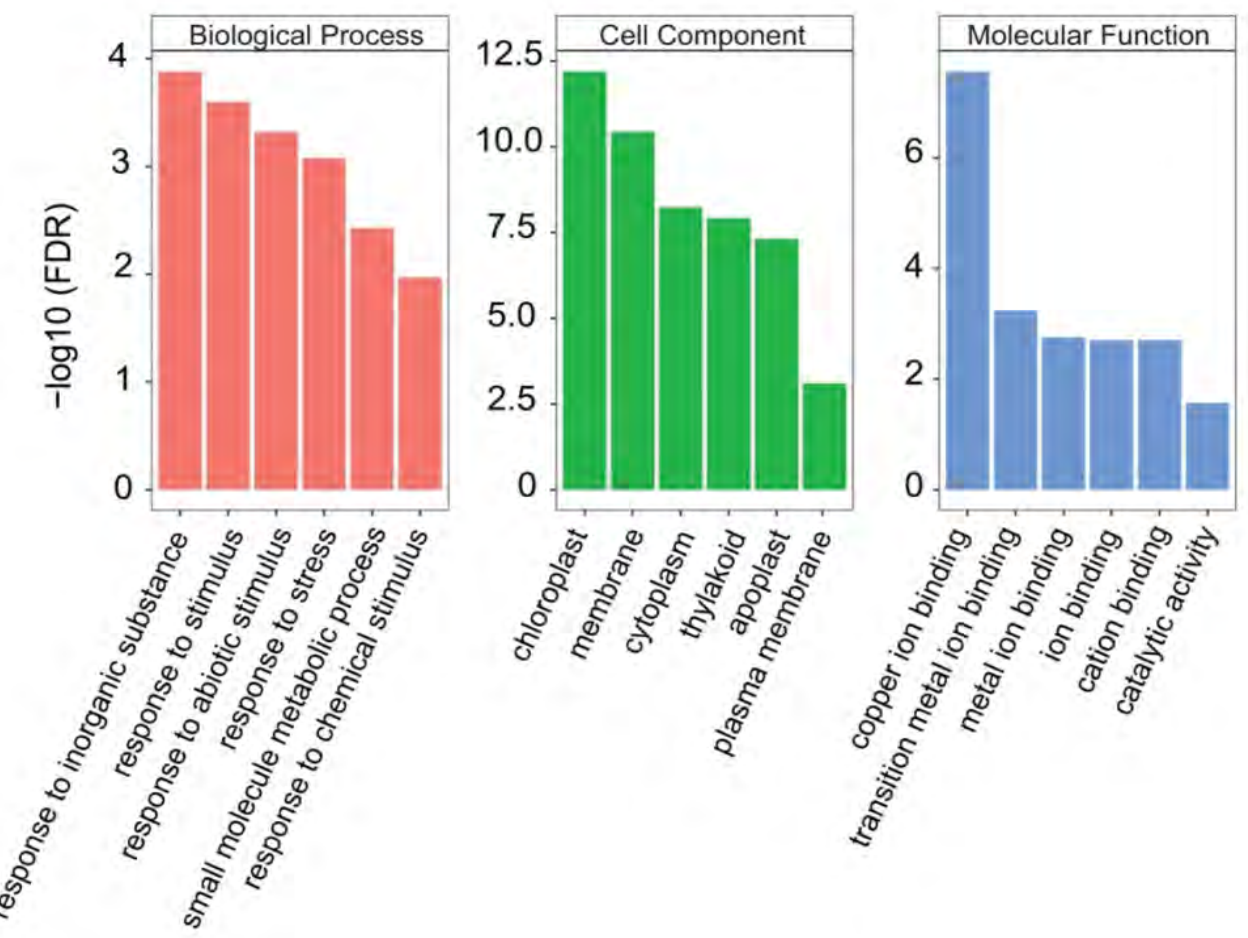

Figure 2: Top six enriched GO terms of differentially abundant proteins in A. thaliana response to narrow-wavelength $595 \mathrm{~nm}$. Red, green, and blue boxes represent GO Biological Process, Cell Component, and Molecular Function, respectively.

ion-binding and catalytic activity. The major KEGG pathways included metabolic pathways (10 DAPs), biosynthesis of secondary metabolites (6 DAPs), and biosynthesis of amino acids (5 DAPs). The GO and KEGG analyses provide an overarching view on the associated biological processes involved in plant response to narrow-wavelength $595 \mathrm{~nm}$ light.

\section{Molecular networks involved in $A$. thaliana Col-0 response to narrow-wavelength $595 \mathrm{~nm}$ light}

To discern the interaction networks for the DAPs identified in A. thaliana response to narrow-wavelength $595 \mathrm{~nm}$ light, a proteinprotein interaction network (PPI) was constructed using the 
Table 2: KEGG pathways enriched by differentially abundant proteins in A. thaliana response to narrow-wavelength $595 \mathrm{~nm}$.

\begin{tabular}{ccccc}
\hline \#term ID & Term description & Count $^{\mathrm{b}}$ & FDR & Matching proteins \\
\hline ath01100 & Metabolic pathways & 10 & $4.94 \mathrm{E}-05$ & $\begin{array}{c}\text { MS1, ATPC1, MS2, FBA8, GAD2, ENO2, } \\
\text { PME3, PSBC, RBCS-1A, TPI }\end{array}$ \\
\hline ath01230 & Biosynthesis of amino acids & 5 & $4.94 \mathrm{E}-05$ & MS1, MS2, FBA8, ENO2, TPI \\
\hline ath00710 & Carbon fixation in photosynthetic organism & 3 & 0.00027 & FBA8, RBCS-1A, TPI \\
\hline ath01200 & Carbon metabolism & 4 & 0.00047 & FBA8, ENO2, RBCS-1A, TPI \\
\hline ath00010 & Glycolysis/gluconeogenesis & 3 & 0.00066 & FBA8, ENO2, TPI \\
\hline ath00450 & Selenocompound metabolism & 2 & 0.00066 & MS1, MS2 \\
\hline ath01110 & Biosynthesis of secondary metabolites & 6 & 0.00087 & MS1, MS2, FBA8, GAD2, ENO2, TPI \\
\hline ath00051 & Fructose and mannose metabolism & 2 & 0.0046 & FBA8, TPI \\
\hline ath00195 & Photosynthesis & 2 & 0.0056 & ATPC1, PSBC \\
\hline ath00270 & Cysteine and methionine metabolism & 2 & 0.011 & MS1, MS2 \\
\hline
\end{tabular}

aPathway ID given by KEGG database.

${ }^{b}$ Number of the involved proteins in protein set.

FDR: False Discovery Rate.

STRING database (Figure 3). This analysis demonstrated that the identified DAPs are highly interconnected. Core central proteins, with high connections in the PPI network, were analyzed using the Cytoscape database. Hub analysis of the network suggested ATPC1, FBA8, and AT5G06290 were central proteins in these networks and in the plant's response to narrow-wavelength 595 $\mathrm{nm}$ light. These proteins play key roles in energy metabolism and redox regulation processes. Clustering analysis of the interaction network further showed two large networks (A and B), consisting of 6 DAPs, which are mainly related to energy metabolism and stress tolerance (Figure 3). Another cluster (C) was not connected to networks $\mathrm{A}$ and $\mathrm{B}$ and was composed of 3 DAPs involved in amino acid metabolism.

\section{Validation of the identified differentially abundant proteins}

To further confirm changes in expression level of the DAPs identified in A. thaliana response to narrow-wavelength $595 \mathrm{~nm}$ light, we leveraged the available labeling proteomics data where eleven-leaves plants of A. thaliana Col-0 were grown under $595 \mathrm{~nm}$, and control light condition, for 5 days [32]. Proteins were extracted from the leaves of treated plants, and subsequently labeled with TMT reagents, then pooled and fractionated followed by LC-MS/ MS/MS analysis. Importantly, we observed a consistent expression pattern for 11 (79\%) of upregulated proteins and $5(56 \%)$ of downregulated proteins in this independent dataset ( $p$-value 0.0384; permutation test).

\section{DISCUSSION}

Previous reports have noted the potential influence of narrowwavelength $595 \mathrm{~nm}$ light on plant stress tolerance [7,14]. We have shown that $595 \mathrm{~nm}$ light regulates genes associated with photosynthetic and antioxidant systems in A. thaliana Col-0 leaves (Yavari et al.). In the present proteomic analysis, a number of 595 $\mathrm{nm}$ light-responsive proteins were identified in A. thaliana Col-0 leaves, implying that this wavelength plays an important in the plant tolerance response.

\section{Proteins involved in photosynthesis}

Photosynthetic machinery reconfigures its components in response J Proteomics Bioinform, Volume 12(8) 139-143
A)

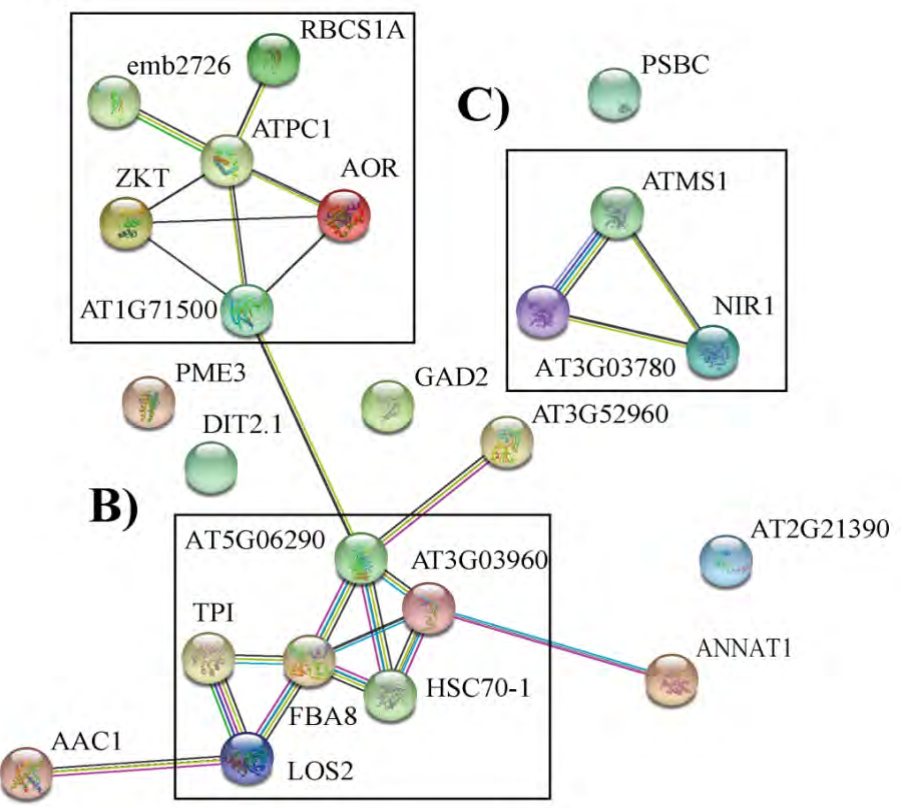

Figure 3: A protein-protein interaction network of differentially abundant proteins in A. thaliana response to narrow-wavelength $595 \mathrm{~nm}$. Confidence level of 0.7 was used for analysis parameters. The different line colors represent the types of evidence used in predicting the associations: neighborhood (green), co-occurrence across genomes (blue), co-expression (black), experimental (purple), association in curated databases (light blue) or texting (yellow).

to changing light conditions [34]. This is true for photosystem II, and many subunits that are involved in light mediation signals [35]. Our proteomic data identified three responsive photosyntheticrelated proteins in chloroplasts that are regulated by $595 \mathrm{~nm}$ light. Among them, a significant increase in expression was observed for the PSII reaction center associated protein, CP43 (PSBC). This protein plays an important role in stabilizing the manganese cluster in the primary water-splitting site within the PSII complex [36,37]. This corroborates with a significant increase in CP43 transcription observed in a recent study on A. thaliana treated with $595 \mathrm{~nm}$ light [38]. This increase suggests that plants have a higher capacity in maintaining the stability of PSII super complex under $595 \mathrm{~nm}$ light, which leads to an enhanced energy transfer from the light 
harvesting antennae to the photosystems [39]. Consistent with this possibility, a significant decrease was observed in the relative abundance of two PSII-associated proteins, the Rieske (2Fe-2S) domain-containing protein PSB33 and MET1. Both proteins are required for PSII assembly in the plant response to light stress signals $[37,40]$. At the same time, a corresponding increase in expression level of GSH2, observed in a recent study on A. thaliana treated with $595 \mathrm{~nm}$ light, could explain further protection within plants photosynthetic machinery under $595 \mathrm{~nm}$ light. Overall, our data suggest a higher tolerance capacity of the PSII super-complex in plants grown under $595 \mathrm{~nm}$ light.

\section{Proteins involved in carbohydrate metabolism}

Plant energy metabolism and the associated proteins can rearrange to boost plant adaptations to light signaling [41,42]. Here, our analysis revealed five carbohydrate metabolism-related proteins whose expression was differentially regulated by $595 \mathrm{~nm}$. Among them, two glycolysis-associated enzymes triosephosphate isomerase (TPI) and enolase 2/transcriptional activator (ENO2) were abundantly upregulated. These two enzymes are essential for plant efficient energy production $[43,44]$. A yeast two-hybrid study demonstrated that these two enzymes interact during glycolysis, and it was proposed that ENO2 regulates the relative abundance of TPI [44]. Importantly, alterations in relative abundance of these two proteins have been reported under abiotic/biotic stress conditions $[45,46]$. Data from this study further suggest that these glycolytic enzymes are involved in maintaining, as well as driving carbon metabolism in plants. There is a possibility that plants have a higher demand for ATP when maintaining metabolic homeostasis under $595 \mathrm{~nm}$ light condition [47]. Consistent with this prospect, our results showed an increase in the abundance of two ATP related proteins: a gamma subunit of the ATP synthase complex (ATPC1), involved in ATP production, and ADP/ATP carrier 1 (AAC1), which mediates the export of generated ATP in the mitochondrion in counter exchange with cytosolic ADP [48]. In agreement with this result, a significant increase in the expression of ATPC1 and members of the ATP synthase complex at protein level was recently reported in A. thaliana Col-0 treated with $595 \mathrm{~nm}$ light $[32,49]$. Relatedly, a recent study suggested higher chloroplast photoprotection and stress tolerance occurs in leaves of A. thaliana treated with $595 \mathrm{~nm}$ light, and this is due to the energy allocation from carbohydrate biosynthesis and accumulation to the production of secondary metabolites [49]. A significant downregulation of the fructose-biphosphate aldolase 8 (FBA8) could further support a restricting flux of generated energy toward the Calvin cycle [49]. Importantly, our analysis identified ATPC1 and FBA 8 as core proteins in interaction networks associated with A. thaliana response to $595 \mathrm{~nm}$ light. Overall, our investigation suggests a high tolerance capacity in plant that is preserved by maintaining and directing the allocation of generated energy when grown under $595 \mathrm{~nm}$ light.

\section{Proteins involved in amino acid metabolism}

Biosynthesis of sulfur/nitrogen containing amino acids supports plant energy requirements for growth and development $[50,51]$ and our results suggest that $595 \mathrm{~nm}$ light potentially impacts expression of proteins involved in amino acid metabolism. Specifically, 5-me thyltetrahydropteroyltriglutamate-homocysteine methyltransferase J Proteomics Bioinform, Volume 12(8) 140-143
1 and 2 (MS1 and MS2) involved in methionine metabolism, were significantly upregulated under $595 \mathrm{~nm}$. In contrast, expression of dicarboxylate transporter 2.1 protein (DIT2-1) and ferredoxinnitrite reductase (NIR1) was downregulated in plants treated 595 $\mathrm{nm}$ light. DIT2-1 is involved in translocating the end product of nitrogen assimilation, glutamate, and NIR1 [52]. Further, it catalyzes the reduction of nitrite to ammonium in the second step of the nitrate-assimilation pathway [53]. This binary pattern suggests that the sulfur uptake ability of plants increased under 595 $\mathrm{nm}$ light, while the seedlings requirement to take up nitrate and ammonium decreased [54]. Sulfur and nitrogen-containing amino acids act as key elements in primary protein structure. Overall, our data imply a key role for these amino acids as building blocks for the synthesis of various proteins that are required for plants' growth and developmental adjustment under $595 \mathrm{~nm}$ light.

\section{Proteins involved in lipid metabolism and transport}

Under high environmental stress, the thylakoid membrane disintegrates the assembled galactolipids, leading to the accumulation of free fatty acids, which are toxic to the cell [55]. In the present study, we noted a significant decrease in relative abundance of quinone oxidoreductase-like protein AT1G23740 (AOR), involved in detoxification of stromal lipid-derived reactive carbonyl species [56]. This result suggests a significant decrease in the accumulation of oxidative-modified biomolecules within chloroplasts that can support an enhanced tolerance capacity for plant chloroplast under $595 \mathrm{~nm}$ light. Thus, these data suggest a significant increase in thylakoid membrane adaptions in plants grown under $595 \mathrm{~nm}$ light.

\section{Proteins involved in cell wall modification}

Our proteomic data indicate that $595 \mathrm{~nm}$ light strongly influences cell wall modification, as evidenced by smaller leaves and elongated petioles; in addition, the pectinesterase/pectinesterase inhibitor 3 enzyme (PME3) was significantly abundant among DAPs. PME3 functions in the modification of cell walls, could act on cell wall plasticity and cell-to-cell adhesion [57]. The involvement of PME3 in response to $595 \mathrm{~nm}$ light signals suggests promoted stem elongation to position leaves at a higher position, with better chances of capturing light energy for photosynthesis. Induction of stem elongation in response to limited light energy has been previously shown [58]. Accordingly, an abundance of PME3 could be of indicative of cell organization that assists a plant's adaptation to $595 \mathrm{~nm}$ light.

\section{Proteins involved in protein synthesis, folding, and degradation}

Molecular chaperones regulate protein quality control in plants [59]. Our results show that $595 \mathrm{~nm}$ light significantly increases the relative abundance of two chaperones, a probable mediator of RNA polymerase II transcription subunit 37e (HSC70-1) and T-complex protein 1 subunit theta (CCT8). The heat shock protein HSC701 is considered a crucial protective mechanism, important in reestablishing and maintaining protein integrity in plant chloroplasts [60]. The chaperonin complex, containing CCT8, enables posttranslocational refolding of transported and targeted proteins in chloroplast $[61,62]$. Overall, results suggest higher adaptation for chloroplasts via protein folding, as well as strengthening protein quality control under $595 \mathrm{~nm}$ light. 


\section{Proteins involved in ROS signaling}

In plant cells, perception of extracellular stimuli is mediated by the plasma membrane receptors $[63,64]$. In the present study, components in $\mathrm{Ca}^{2+}$ and ROS signaling were differentially regulated under $595 \mathrm{~nm}$ light when compared to control FL light. A significant increase was observed in the relative abundance of $\mathrm{Ca}^{2+}$-dependent membrane-binding protein annexin 1 (ANN1), which serves as important component in stress tolerance and maintaining $\mathrm{Ca}^{2+}$ homeostasis in plants $[65,66] . \mathrm{Ca}^{2+}$ plays an essential role in plant cells in response to environmental stimuli as a second messenger [67]. ANN1 plays a regulatory role in ROS signal transduction in a $\mathrm{Ca}^{2+}$-dependent manner in Arabidopsis $[68,69]$. Moreover, our results showed a high relative abundance of glutamate decarboxylase 2 (GAD2), the key enzyme involved in gamma-aminobutyric acid (GABA) biosynthesis [70]. GABA has an important function in plant developmental processes and stress responses [71,72]. Elevated GABA levels are dependent on the calmodulin domain of calcium-sensing proteins in response to cytosolic $\mathrm{Ca}^{2+}$ oscillations that occur with different environmental stresses [73]. Congruent with the potential effect of $595 \mathrm{~nm}$ light on ROS signaling-associated proteins, we observed that $595 \mathrm{~nm}$ has a significant regulatory role in activating plant antioxidant capacity, leading to higher chloroplast protection [49]. Overall, these data suggest that the calcium ion-associated signaling pathways play a pivotal role in enhancing plant adaptation, and tolerance to 595 nm light.

\section{Proteins involved in redox signaling}

Redox regulation is an essential defense response to stress conditions [74]. We observed a significant decrease in the abundance of two enzymes in the peroxiredoxin family; peroxiredoxin-2E (PRXIIE) and 2-Cys peroxiredoxin BAS1-like (AT5G06290). Under oxidative stress, PRXIIE plays an important function in the redoxsystem mechanisms that control $\mathrm{H}_{2} \mathrm{O}_{2}$ levels towards preserving chloroplast integrity [75] and 2-Cys peroxiredoxin BAS1-like protein functions in $\mathrm{H}_{2} \mathrm{O}_{2}$ detoxification [76]. Lower relative abundance of these two peroxiredoxin enzymes suggests sustaining intracellular redox homeostasis, requirements for $\mathrm{H}_{2} \mathrm{O}_{2}$ scavenging, in plant chloroplast under $595 \mathrm{~nm}$ light [77]. Overall, these data suggest that stable redox homeostasis results in higher adaptation capacity for plants growing under $595 \mathrm{~nm}$ light.

\section{CONCLUSION}

Here, the LC-LTQ methodology applied to Arabidopsis thaliana is the first unbiased proteomic study aimed towards the identification of molecular processes associated with a plant's response to narrow wavelength $595 \mathrm{~nm}$ light. A number of proteins were identified that several of which could be involved in plant tolerance response. Although these data indicate that A. thaliana modifies its proteome upon exposure to $595 \mathrm{~nm}$ light, proteome coverage obtained here is low. Proteins involved in carbohydrate and amino acid metabolism were in greater abundance in plants treated with 595 $\mathrm{nm}$ light. Furthermore, molecular chaperones and PSII-associated membrane proteins showed significant changes in abundance. The comparative phenotype analysis suggests that $595 \mathrm{~nm}$ light also affects the cell wall proteome.

\section{AUTHOR CONTRIBUTIONS}

NY and ML designed the experiments. NY performed the experiments and analyzed the data. ML contributed reagents/ materials/analysis tools and supervised the project. NY and ML wrote the manuscript. All authors read and approved the final manuscript.

\section{FUNDING}

This work was supported by the Natural Sciences and Engineering Research Council of Canada (NSERC; grant number RGPIN 355743-13, CRDPJ418919-11).

\section{CONFLICT OF INTEREST STATEMENT}

The authors declare that the research was conducted in the absence of any commercial or financial relationships that could be construed as a potential conflict of interest.

\section{REFERENCES}

1. Gupta SD, Agarwal A. Artificial lighting system for plant growth and development: chronological advancement, working principles, and comparative assessment. Light Emitting Diodes for Agriculture: Springer. 2017;1-25.

2. Pinho $P$, Halonen L. Agricultural and horticultural lighting. Handbook of Advanced Lighting Technology. 2017:703-720.

3. Bisbis MB, Gruda N, Blanke M. Potential impacts of climate change on vegetable production and product quality-A review. J Clean Prod. 2018; 170:1602-1620.

4. Pocock T. Light-emitting diodes and the modulation of specialty crops: Light sensing and signaling networks in plants. Hort Science. 2015;50(9):1281-1284.

5. Terashima I, Fujita T, Inoue T, Chow WS, Oguchi R. Green light drives leaf photosynthesis more efficiently than red light in strong white light: revisiting the enigmatic question of why leaves are green. Plant Cell Physiol. 2009;50(4):684-697.

6. Smith HL, McAusland L, Murchie EH. Don't ignore the green light: exploring diverse roles in plant processes. J Exp Bot. 2017;68(9):2099. 2110.

7. Wang H, Gu M, Cui J, Shi K, Zhou Y, Yu J. Effects of light quality on $\mathrm{CO} 2$ assimilation, chlorophyll-fluorescence quenching, expression of Calvin cycle genes and carbohydrate accumulation in Cucumis sativus. J Photochem Photobiol B. 2009;96(1):30-37.

8. Wu Q, Su N, Shen W, Cui J. Analyzing photosynthetic activity and growth of Solanum lycopersicum seedlings exposed to different light qualities. Acta Physiologiae Plantarum. 2014;36(6):1411-1420.

9. Yan M, Wang M, Wang H, Wang Y, Zhao C. Effects of light quality on photosynthetic pigment contents and photosynthetic characteristics of peanut seedling leaves. Ying Yong Sheng Tai Xue Bao. 2014;25(2):483-487.

10. Tanaka A, Ohno N, Nakajima K, Matsuda Y. Light and CO2/cAMP signal cross talk on the promoter elements of chloroplastic I-carbonic anhydrase genes in the marine diatom Phaeodactylum tricornutum. Plant Physiol. 2016;170(2):1105-1116.

11. Wang H, Gu M, Cui J, Shi K, Zhou Y, Yu J. Effects of light quality on $\mathrm{CO} 2$ assimilation, chlorophyll-fluorescence quenching, expression of Calvin cycle genes and carbohydrate accumulation in Cucumis sativus. J Photochem Photobiol B: Biol. 2009;96(1):30-37.

12. Brazaitytė A, Duchovskis P, Urbonavičiūtė A, Samuolienė G, 
Jankauskienė J, Sakalauskaitė J, et al. The effect of light-emitting diodes lighting on the growth of tomato transplants. Zemdirbyste-Agri. 2010;97(2):89-98.

13. McCree KJ. Significance of enhancement for calculations based on the action spectrum for photosynthesis. Plant Physiol. 1972;49(5):704-706.

14. Yu W, Liu Y, Song L, Jacobs DF, Du X, Ying Y, et al. Effect of differential light quality on morphology, photosynthesis, and antioxidant enzyme activity in Camptotheca acuminata seedlings. J Plant Growth Regul. 2017;36(1):148-160.

15. Chen XW, Liu SQ, Wang Y, Liu JK, Feng L. Effects of different LED light qualities on growth, photosynthetic characteristics and nutritional quality of savoy. Ying Yong Sheng Tai Xue Bao. 2014;25(7):1955-1962.

16. Higuchi Y, Hisamatsu T. Light acts as a signal for regulation of growth and development. LED lighting for urban agriculture: Springer. 2016;57-73.

17. Larner VS, Franklin KA, Whitelam GC. Photoreceptors and light signalling pathways in plants. Annu Rev Plant Biol. 2018:107-131.

18. Gupta SD, Pradhan S. Regulation of gene expression by LED lighting. Light Emitting Diodes for Agriculture: Springer. 2017;237-258.

19. Rajjou L, Gallardo K, Job C, Job D. Proteome analysis for the study of developmental processes in plants. Annu Plant Rev Online. 2018:151-184.

20. Brautigam K, Dietzel L, Kleine T, Stroher E, Wormuth D, Dietz KJ, et al. Dynamic plastid redox signals integrate gene expression and metabolism to induce distinct metabolic states in photosynthetic acclimation in Arabidopsis. Plant Cell. 2009;21(9):2715-2732.

21. Hoagland DR, Arnon DI. The water-culture method for growing plants without soil. Berkely,: The College of Agriculture. 1950;32.

22. Huang EL, Orsat V, Shah MB, Hettich RL, VerBerkmoes NC, Lefsrud MG. The temporal analysis of yeast exponential phase using shotgun proteomics as a fermentation monitoring technique. J Proteomics. 2012;75(17):5206-5214.

23. Verberkmoes NC, Russell AL, Shah M, Godzik A, Rosenquist M, Halfvarson J, et al. Shotgun metaproteomics of the human distal gut microbiota. ISME J. 2009;3(2):179-189.

24. McDonald WH, Ohi R, Miyamoto DT, Mitchison TJ, Yates III JR. Comparison of three directly coupled HPLC MS/MS strategies for identification of proteins from complex mixtures: single-dimension LC-MS/MS, 2-phase MudPIT, and 3-phase MudPIT. Int J Mass Spectrom. 2002;219(1):245-251.

25. McDonald WH, Tabb DL, Sadygov RG, MacCoss MJ, Venable J, Graumann J, et al. MS1, MS2, and SQT-three unified, compact, and easily parsed file formats for the storage of shotgun proteomic spectra and identifications. Rapid Communications in Mass Spectrom. 2004;18(18):2162-2168.

26. Carvalho PC, Lima DB, Leprevost FV, Santos MD, Fischer JS, Aquino PF, et al. Integrated analysis of shotgun proteomic data with PatternLab for proteomics 4.0. Nat Protoc. 2016;11(1):102.

27. Eng JK, Jahan TA, Hoopmann MR. Comet: an open】source MS/MS sequence database search tool. Proteomics. 2013;13(1):22-24.

28. Xu T, Park S, Venable J, Wohlschlegel J, Diedrich J, Cociorva D, et al. ProLuCID: An improved SEQUEST-like algorithm with enhanced sensitivity and specificity. J Proteomics. 2015;129:16-24.

29. Carvalho PC, Fischer JS, Xu T, Cociorva D, Balbuena TS, Valente $\mathrm{RH}$, et al. Search engine processor: filtering and organizing peptide spectrum matches. Proteomics. 2012;12(7):944-949.

30. Zhang Y, Wen Z, Washburn MP, Florens L. Refinements to label free proteome quantitation: how to deal with peptides shared by multiple

J Proteomics Bioinform, Volume 12(8) 142-143 proteins. Anal Chem. 2010;82(6):2272-2281.

31. Carvalho PC, Hewel J, Barbosa VC, Yates III JR. Identifying differences in protein expression levels by spectral counting and feature selection. Genet Mol Res. 2008;7(2):342.

32. Yavari N, Kushalappa A, Lefsrud MG. In-depth comparative proteomic analysis of Arabidopsis thaliana response to narrow-wavelength lights reveals regulation of proteome profiles controlling biological functions.

33. Shannon P, Markiel A, Ozier O, Baliga NS, Wang JT, Ramage D, et al. Cytoscape: a software environment for integrated models of biomolecular interaction networks. Genome Res. 2003;13(11):2498-2504.

34. Rochaix JD. Plant science. Fine-tuning photosynthesis. Science. 2013;342(6154):50-51.

35. Järvi S, Suorsa M, Aro EM. Photosystem II repair in plant chloroplasts-regulation, assisting proteins and shared components with photosystem II biogenesis. Biochimica et Biophysica Acta (BBA)Bioenergetics. 2015;1847(9):900-909.

36. Qian H, Chen W, Li J, Wang J, Zhou Z, Liu W, et al. The effect of exogenous nitric oxide on alleviating herbicide damage in Chlorella vulgaris. Aquat Toxicol. 2009;92(4):250-257.

37. Fristedt R, Trotta A, Suorsa M, Nilsson AK, Croce R, Aro EM, et al. PSB33 sustains photosystem II D1 protein under fluctuating light conditions. J Exper Bot. 2017;68(15):4281-4293.

38. Yavari N. An integrated approach to unravel the physiological and molecular basis of Arabidopsis thaliana response to narrow-wavelength lights.

39. Zhou F, Qiu N, Gu Z, Zhang B, Hua C. Thermal stability studies of photosystem II complexes reconstituted into phosphatidylcholine liposomes. Russian J Plant Physiol. 2014;61(1):26-32.

40. Bhuiyan NH, Friso G, Poliakov A, Ponnala L, van Wijk KJ. MET1 is a thylakoid-associated TPR protein involved in photosystem II supercomplex formation and repair in Arabidopsis. Plant Cell. 2015;27(1):262-285.

41. Kieffer P, Planchon S, Oufir M, Ziebel J, Dommes J, Hoffmann L, et al. Combining proteomics and metabolite analyses to unravel cadmium stress-response in poplar leaves. J Proteome Res. 2008;8(1):400-417.

42. Jin H, Xu M, Chen H, Zhang S, Han X, Tang Z, et al. Comparative proteomic analysis of differentially expressed proteins in Amaranthus hybridus L. roots under cadmium stress. Water Air Soil Poll. 2016;227(7):220.

43. Trujillo C, Blumenthal A, Marrero J, Rhee KY, Schnappinger D, Ehrt S, et al. Triosephosphate isomerase is dispensable in vitro yet essential for Mycobacterium tuberculosis to establish infection. MBio. 2014;5(2):e00085-14.

44. Zhang YH, Chao C, Shi ZH, Cheng HM, Jie B, Zheng CX, et al. Identification of salinity-related genes in ENO2 mutant (eno2!) of Arabidopsis thaliana. J Integr Agric. 2018;17(1):94-110.

45. Morris AC, Djordjevic MA. Proteome analysis of cultivarlspecific interactions between Rhizobium leguminosarum biovar trifolii and subterranean clover cultivar Woogenellup. Electrophoresis. 2001;22(3):586-598.

46. Dumont S, Rivoal J. Consequences of oxidative stress on plant glycolytic and respiratory metabolism. Front. Plant Sci. 2019;10.

47. Wang L, Jin X, Li Q, Wang X, Li Z, Wu X, et al. Comparative proteomics reveals that phosphorylation of $\square$ carbonic anhydrase 1 might be important for adaptation to drought stress in Brassica napus. Sci Rep. 2016;6:39024.

48. Haferkamp I. The diverse members of the mitochondrial carrier family in plants. FEBS Lett. 2007;581(12):2375-2379. 
49. Yavari N, Tripathi RK, Wu B, MacPherson S, Singh J, Lefsrud MG, et al. Photosynthetic performance of Arabidopsis thaliana accessions to different light wavelengths.

50. Ye X, She M, Wang K, Xu H. Identification, cloning, and potential application of genes related to somatic embryogenesis in plant tissue culture. Acta Agronomica Sinica. 2012;38(2):191-201.

51. Shi J, Zang X, Cong X, Hou L, He B, Ding Y, et al. Cloning of nitrite reductase gene from Haematococcus pluvialis and transcription and enzymatic activity analysis at different nitrate and phosphorus concentration. Gene. 2019;697:123-130.

52. Renné P, Dreßen U, Hebbeker U, Hille D, Flügge UI, Westhoff P, et al. The Arabidopsis mutant det is deficient in the plastidic glutamate/ malate translocator DiT2. Plant J. 2003;35(3):316-331.

53. Mai HJ, Bauer P. From the proteomic point of view: Integration of adaptive changes to iron deficiency in plants. Curr Plant Biol. 2016;5:45-56.

54. Hoefgen R, Nikiforova VJ. Metabolomics integrated with transcriptomics: assessing systems response to sulfur-deficiency stress. Physiol Plant. 2008;132(2):190-198.

55. Sgherri C, Pinzino C, Quartacci MF. Reactive oxygen species and photosynthetic functioning: past and present. Reactive Oxygen Species in Plants: Boon or Bane-Revisiting the Role of ROS: J. Wiley \& Sons, Ltd, Chichester, UK; 2018. Pp:137-155.

56. Curien G, Giustini C, Montillet JL, Mas-y-Mas S, Cobessi D, Ferrer $\mathrm{JL}$, et al. The chloroplast membrane associated ceQORH putative quinone oxidoreductase reduces long-chain, stress-related oxidized lipids. Phytochemistry. 2016;122:45-55.

57. Santi C, Molesini B, Guzzo F, Pii Y, Vitulo N, Pandolfini T, et al. Genome-Wide Transcriptional Changes and Lipid Profile Modifications Induced by Medicago truncatula N5 Overexpression at an Early Stage of the Symbiotic Interaction with Sinorhizobium meliloti. Genes. 2017;8(12):396.

58. Casal JJ. Shade avoidance. The Arabidopsis book / American Society of Plant Biologists. 2012;10:e0157.

59. Berner N, Reutter K-R, Wolf DH. Protein quality control of the endoplasmic reticulum and ubiquitin-proteasome-triggered degradation of aberrant proteins: Yeast pioneers the path. Annu Rev Biochem. 2018;87:751-782.

60. Jarvi S, Suorsa M, Tadini L, Ivanauskaite A, Rantala S, Allahverdiyeva Y, et al. Thylakoid-Bound FtsH Proteins Facilitate Proper Biosynthesis of Photosystem I. Plant Physiol. 2016;171(2):1333-1343.

61. Horwich AL, Fenton WA, Chapman E, Farr GW. Two families of chaperonin: physiology and mechanism. Annu Rev Cell Dev Biol. 2007;23:115-145.

62. Xu XM, Wang J, Xuan Z, Goldshmidt A, Borrill PG, Hariharan N, et al. Chaperonins facilitate KNOTTED1 cell-to-cell trafficking and stem cell function. Science. 2011;333(6046):1141-1144.

63. Demidchik V, Shabala S, Isayenkov S, Cuin TA, Pottosin I. Calcium transport across plant membranes: mechanisms and functions. New Phytologist. 2018;220(1):49-69.

64. Singh A, Kumar A, Yadav S, Singh IK. Reactive oxygen speciesmediated signaling during abiotic stress. Plant Gene. 2019:100173.

65. Wang P, Li Z, Wei J, Zhao Z, Sun D, Cui S, et al. A Na+/Ca2+ exchanger-like protein (AtNCL) involved in salt stress in Arabidopsis. J Biol Chem. 2012;287(53):44062-44070.

66. Singh AK, Kumar R, Tripathi AK, Gupta BK, Pareek A, Singla-Pareek $\mathrm{SL}$, et al. Genome-wide investigation and expression analysis of Sodium/Calcium exchanger gene family in rice and Arabidopsis. Rice. 2015;8(1):21.

67. Pei ZM, Gilroy S. Calcium signals and their regulation. Annu Rev Plant Biol. 2018:137-162.

68. Laohavisit A, Richards SL, Shabala L, Chen C, Colaço RD, Swarbreck $\mathrm{SM}$, et al. Salinity-induced calcium signaling and root adaptation in Arabidopsis require the calcium regulatory protein annexin 1 . Plant Physiol. 2013;163(1):253-262.

69. Zipfel C, Oldroyd GE. Plant signalling in symbiosis and immunity. Nature. 2017;543(7645):328.

70. Schousboe A. Metabolic signaling in the brain and the role of astrocytes in control of glutamate and GABA neurotransmission. Neurosci Lett 2019;689:11-13.

71. Majumdar R, Barchi B, Turlapati SA, Gagne M, Minocha R, Long S, et al. Glutamate, ornithine, arginine, proline, and polyamine metabolic interactions: the pathway is regulated at the post-transcriptional level. Front Plant Sci. 2016;7:78.

72. Ma Y, Wang P, Wang M, Sun M, Gu Z, Yang R, et al. GABA mediates phenolic compounds accumulation and the antioxidant system enhancement in germinated hulless barley under $\mathrm{NaCl}$ stress. Food Chem. 2019;270:593-601.

73. Shelp BJ, Bown AW, Zarei A. 4-Aminobutyrate (GABA): a metabolite and signal with practical significance. Botany. 2017;95(11):1015-1032.

74. Sies H. Oxidative Stress: Eustress and Distress in Redox Homeostasis. Stress: Physiology, Biochemistry, and Pathology: Elsevier; 2019. Pp:153-163.

75. Das P, Nutan KK, Singla-Pareek SL, Pareek A. Oxidative environment and redox homeostasis in plants: dissecting out significant contribution of major cellular organelles. Front Environ Sci. 2015;2:70.

76. Dietz KJ, Jacob S, Oelze ML, Laxa M, Tognetti V, de Miranda $\mathrm{SMN}$, et al. The function of peroxiredoxins in plant organelle redox metabolism. J Exp Bot. 2006;57(8):1697-709.

77. Silva FD, Vasconcelos IM, Saraiva KD, Costa JH, Fernandes CF, Oliveira JT, et al. The expression of the genes involved in redox metabolism and hydrogen peroxide balance is associated with the resistance of cowpea [Vigna unguiculata (L.) Walp.] to the hemibiotrophic fungus Colletotrichum gloeosporioides. J Plant Physiol. 2019;233:73-83. 